ations of accommodation are smaller; in fact so small that they are almost negligible in practice, especially for a congenital anisometrope. These variations are still less important when they are evaluated in relation to the distance from the eye to the hind sight, which is larger for the revolver than for the rifie. The angles of convergence are therefore relatively smaller.
The officer mentioned at the beginning of this article fulfilled to a nicety the conditions required for binocular aiming. The difference between his eyes is $0.75 \mathrm{D}$. He therefore is an exception, and it is hardly possible that any of the young soldiers he instructed had really learned to aim in the same manner as their master, tho the latter was convinced that they had.

\title{
RECURRENT HEMORRHAGES INTO THE RETINA AND VITREOUS OF YOUNG PERSONS.
}

\author{
William C. Finnoff, M.D., Oph.D. \\ DENVER, COLORADO.
}

This paper is based on five cases encountered by the writer, the histories of which are here included, and the cases found reported in the literature, 110 in all. It was read before the American Ophthalmological Society in June, 1921, accompanied by elaborate tables of cases apparently due to tuberculosis, syphilis, gastrointestinal trouble, focal infections, menstrual disturbances, and disturbances of blood and circulation, with undetermined causes in 51 cases. The principal conclusions drawn from this study are here given. The detailed tables are published in the Transactions of the American Ophthalmological Society.

The symptom complex of recurring hemorrhages into the retina and vitreous, followed by retinitis proliferans in young persons, has been well understood by ophthalmologists for many years. The predisposition of some young men to spontaneous hemorrhages into the eye was first described by von Graefe ${ }^{1}$ in 1854. Modern textbooks refer to this condition, and considerable space is allotted to it in the American Encyclopedia of Ophthalmology. ${ }^{2}$ The etiology of this condition, however, has not yet emerged from the realm of speculation.

Forty years ago, Eales ${ }^{3}$ accurately described the symptoms and course of recurrent retinal hemorrhages. His cases occurred in males between the ages of fourteen and twenty years. The left eye was first affected. There had been a history of epistaxis and constipation in most of the cases, and the author attributed the condition to a neurosis which affected the digestive and circulatory systems. Eales believed that the disease did not occur in women, and that menstruation acted as a safeguard.

Panas called the condition "Ocular Epistaxis," and noted that in the young the hemorrhage was from the veins, whereas in the old the bleeding was from the arteries. Beaumont ${ }^{4}$ and others have reported cases associated with epistaxis.

In 1882 Hutchinson $^{5}$ advanced the theory, that some cases of recurrent retinal hemorrhages occurring during adolescence were due to congenital gout. Leber suggested oxaluria as a cause, and Jacqueau ${ }^{6}$ reported a case which he thought was due to a phosphaturia and excess of urea. The hemorrhages in this case recurred over a period of sixteen years. Syphilis, both congenital and acquired, has been advanced as an etiologic factor.

Noll, ${ }^{7}$ in 1908 , was the first to suggest tuberculosis as a cause of recurrent hemorrhages into the retina and vitreous.

In $1909 \mathrm{Kipp}^{8}$ described a case of recurrent hemorrhage into the retina and vitreous of both eyes in a young man with tuberculosis of the hip and chronic otitis media. The hemorrhages were followed by retinitis proliferans. A second case, which he had reported before this Society in $1895,{ }^{\circ}$ occurred in a young man who had a cough and lost weight shortly after the occur- 
rence of the retinal hemorrhages, but who later regained perfect health. Kipp suggested that these cases were of a possible tuberculous nature. Axenfeld's ${ }^{10}$ article in 1910 called attention to the fact that recurrent retinal and vitreous hemorrhages were often due to tuberculosis, even tho no apparent tuberculous changes had occurred elsewhere in the eye. This author reported 3 cases to support his view. He believed that the lesions were due either to the tubercle bacilli or to the actions of their toxins, and that the individuals suffering from the disease were frequently robust and apparently in good health. Improvement followed the administration of tuberculin in Axenfeld's cases, and he advised its use as a diagnostic and therapeutic measure. Since Axenfeld's observations, Igersheimer, ${ }^{11}$ Harms, ${ }^{12}$ Jackson, ${ }^{13}$ and many others have reported cases due to tuberculosis. (See tables.)

Toxemia has been suggested by Moissonnier ${ }^{14}$ as a cause; and recently Zentmayer ${ }^{15}$ has called atțention to the possibility of derangements of the endocrine organs, especially the adrenals, as a contributing factor.

Hemophilia, disorders of menstruation, indicanuria, excessively high or low blood pressure, the anemias, nephritis, exercise, and other conditions have been mentioned as possible causative factors in the production of recurrent intraocular hemorrhage in the young.

In the past six months there have come under my care three young men with recurrent massive hemorrhages into the retina and vitreous. I have been impressed by the similarity of the symptoms in these and other cases that I have seen. In attempting to determine the basic etiology of the hemorrhages, my interest in this disease was sufficiently aroused to search the literature to see what had been written on this subject.

The following reports are of cases which have come under my care since 1916:

CASE 1. A farmer, aged twenty-eight years, had massive recurrent hemorrhages into the retina and vitreous of the right eye, following a periphlebitis of the retinal veins. A focal reaction to tuberculin was obtained. The hemorrhages remained confined to the right eye. Jackson reported this case with other cases of tuberculosis of the retina before this Society in 1919, and I will refer you to the Transactions for the details of this case.

Case 2. W. P. B., aged forty-two years, seen first May 16, 1919. Three years before he had developed pulmonary tuberculosis, and had come to Colorado, where he rapidly regained his health. For three years he had felt well and had not coughed. The vision of the left eye always had been poor, probably from an amblyopia ex anopsia. History otherwise negative. One year prior to consultation, the vision of both eyes had blurred suddenly; it gradually improved, but did not regain its former acuity and floaters have been present ever since. May 12,1919 , the vision became suddenly clouded. There had been no pain or discomfort in the eyes at the time of the blurring or since. When first seen, V.R.E., 0.05 ; L.E., 0.2. The right vitreous contained small masses of blood; these were more numerous in the lower half. The remainder of the vitreous was uniformly hazy. A hammock shaped subhyaloid hemorrhage, with its convexity downward, was noted, extending from the lower temporal vein to the lower nasal vein. The veins were uniformly distended and tortuous. A perivascular, yellowish exudate, covering one of the terminal branches of the upper temporal vein, was seen. The Wassermann reaction and urinc. were negative. There was no history or evidence of infection in the tonsils or nasal sinuses; and X-rays and examinations of the teeth and jaws were negative. The systolic blood pressure was $122 \mathrm{~mm}$. of mercury. Upon physical examination, a small cavity was found in the apex of the right lung. It was thought advisable not to use tuberculin in this case, because of the danger of lighting up a latent tuber- 
culous focus in the lung, so the patient was sent to a sanatorium for general hygienic treatment. In a letter from the patient, received six months later, he stated that he had gained greatly in general health, and that his vision had improved.

CASE 3 . This case was reported also by Dr. Edward Jackson (13, case 3) in the same paper as Case 1. In 1915 the patient, a male, aged twenty-five years, had the first hemorrhage in the right vitreous. Six months after the onset he consulted Dr. Arnold Knapp, of New York City, who pronounced eye was suddenly obscured in the upper field. He had been free from trouble for so long that he had disregarded his general health and was run down because of overwork indoors. Dr. Jackson referred the patient to me, and I found, V.R.E., light perception; L.E., 0.8. The fundus of the right eye was the same as reported in 1917. The vitreous of the left eye was uniformly hazy. A large, hamnock shaped subhyaloid hemorrhage was noted in the lower portion of the eyc, extending from a mass of retinitis proliferans on the temporal side, near one of the

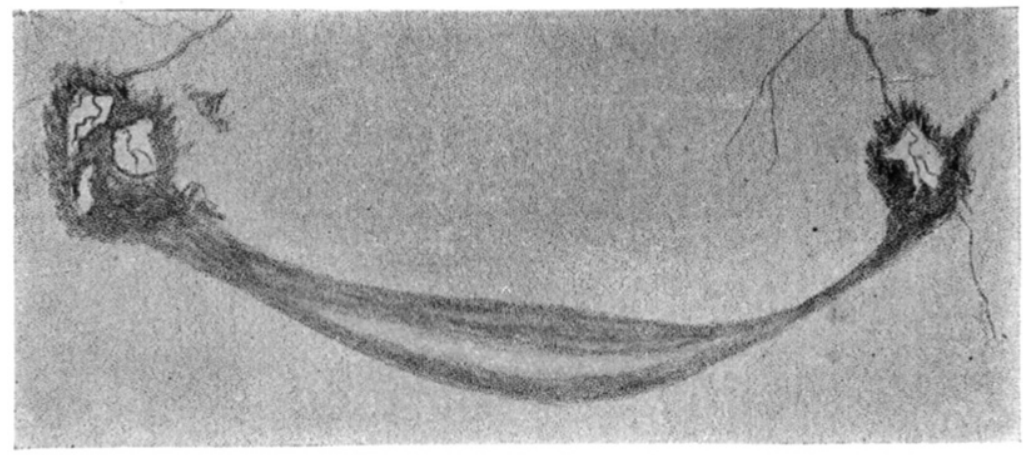

Fig. 1.-Retinitis proliferans. Subhyoid hemorrhages. Hemorrhages into the retina.

the condition tuberculosis and put him on tuberculin. There was temporary improvement, but later a recurrence of activity, with great loss of vision in the right eye. In December, 1916 when he was first seen by Dr. Jackson, V.R.E., moving fingers at 1 foot; L.E., with correction, 1.1. The right vitreous was cloudy; no fundus details were visible. There was a grayish-red reflex in all directions and floating masses, which in the lower temporal vitreous looked almost like detached retina, but no vessels were found. Left eye, slight haziness of vitreous. Choroid rather patchy and "moth eaten," otherwise the fundus was normal. Infiltration of the apices of the lungs, especially the right, was found. Two hemorrhages occurred into the vitreous of the right eye-one in February and the other in April of 1917. The eyes then remained quiet until November 10,1921 , when the vision of the left terminal branches of the lower temporal vein, to a second similar mass along the first branch of the lower nasal vein (Fig. 1). A smaller subhyaloid hemorrhage was seen about 4 d.d. above the nerve head, in the region of a scar which covered a vertical vein. 'There were hemorrhages into the retina surrounding the masses of scar tissue. The blood absorbed slowly and was replaced, in part, by bands of scar tissuc. Tuberculin in small doses $(1 / 500,000 \mathrm{mgm}$.) was given and gradually increased. December 23, twenty-four hours after the administration of a dose of $1 / 100,000$ mgm. of tuberculin, new retinal hemorrhages occurred. This was a focal reaction, and the size of the dose was diminished. January 13, 1921, V.L.E., 1.1. January 19, during the excitement of making a political speech, contrary to instructions, the vision suddenly became obscured, due to a hem- 
orrhage into the lower vitreous in about the same location as the former one. The blood absorbed more slowly, and when last seen March 8, there was still some haziness of the lower vitreous and dark blood in the retina around the scar tissue. The patient was ordered to stop work and was sent to a sanatorium, where he could be under supervision. He reported a few weeks ago that he had improved greatly in general health, and that there had been no new hemorrhages. pounds after the extraction of six decayed teeth. About two and one-half years ago he had a serere attack of influenza, but recovered without complications. In December, 1920, he had acute tonsillitis. Since childhood he has had frequent attacks of epistaxis, but has not had bleeding from the nose for several months. He has never suffered from constipation. V.R.F.. 0.0s: L.E., 1.1. Ophthalmoscope: Cornea and lens clear; vitreous clouded, due to the presence of blood. Only the ex-

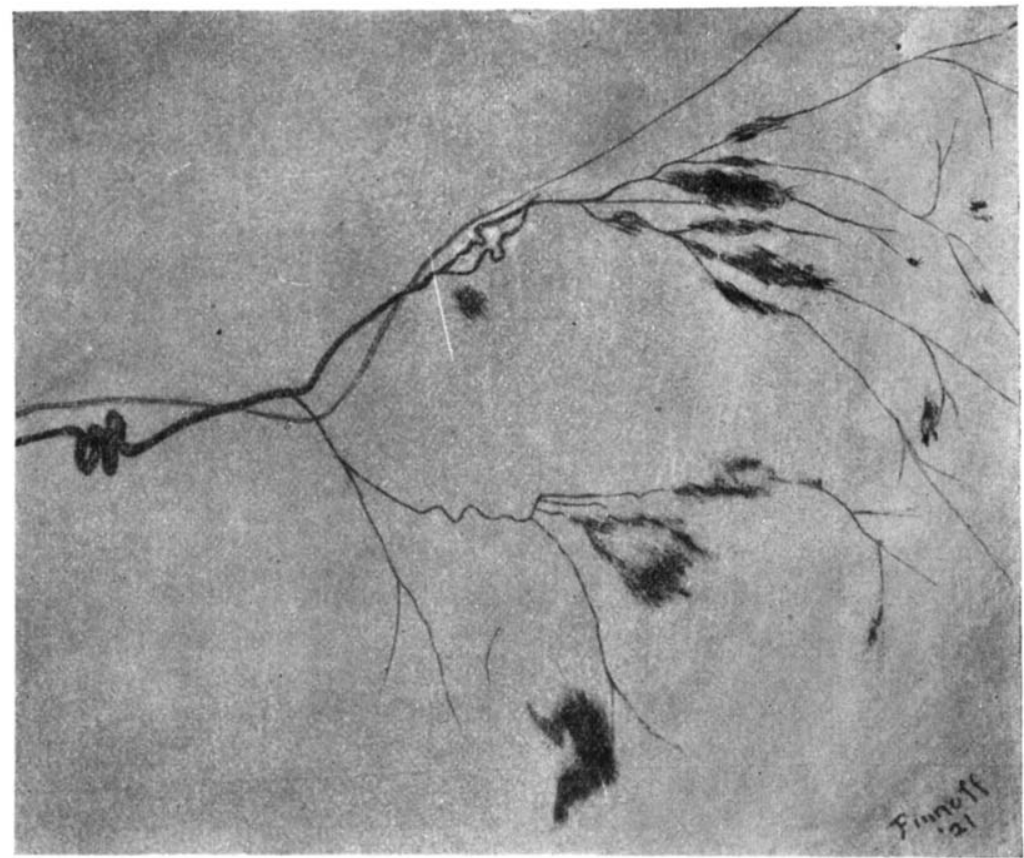

Fig. 2.- Tortuous and distended veins. Venous hemorrhages into retina. Perivascular exulates and

CASE 4. K.F.F., aged thirty-five years, first seen April 2, 1921. Two weeks before, while walking, the vision of the right eye suddenly became hazy; the vision gradually improved, until April 1, when the vision in the same eye was almost completely lost. The second attack occurred while he was sitting at his desk writing.

There was no history of tuberculosis or hemophilia in his family. He had the usual diseases of childhood without complications. Four years ago he had severe articular rheumatism, which cleared up, and he gained 40 treme nasal side of the fundus could be seen. In this portion the upper nasal vein was found to be distended and tortuous, and did not diminish in size toward the periphery, distally to the entrance of good sized contributing branches. In the peripheral portion, two veins were distended and tortuous. They were bordered, for a short distance, by a fine white exudate into which one of the veins finally disappeared. The accompanying artery was obscured by exudate in this region. A small retinal hemorrhage was seen slightly below the area of 
exudation. Further to the periphery, numerous hemorrhages of venous origin were seen in the retina. In the extreme periphery, as far forward as one could see, the retina contained a silvery white exudate. The vessels were visible over this portion of the retina, and several small areas of hemorrhage were noted in it (Fig. 2). In the lower portion of the eye, large subhyaloid and vitreous hemorrhages were seen. Left eye: the media were clear. The veins were slightly distended, but showed no signs of disease, otherwise, the fundus was normal.

Blood Wassermann, blood counts, and urine were negative. Systolic blood pressure, $118 \mathrm{~mm}$. of mercury. Coagulation time of blood (capillary tube method), four minutes, twenty seconds. Two apical abscesses were found in X-ray pictures of the teeth. The invalved teeth were removed, and the abscesses drained. The surgeon thought the tonsils did not show pathology enough for removal. April 12,

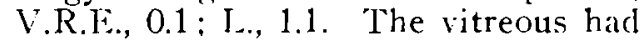
cleared slightly, but no further details could be made out. Old tuberculin, 0.005 mgm., was given subcutaneously, with no local, constitutional, or focal reaction. Increasing doses of tuberculin were injected every forty-eight hours until a $5 \mathrm{mgm}$. dose had been given; no reaction was obtained, and tuberculosis was excluded as the etiology. It was insisted upon that the tonsils be removed, to exclude every possible focus of infection, and potassium iodid and thyroid extract were prescribed.

May 16, the vitreous had cleared considerably since the last examination. The outline of the disc could be seen. A number of small retinal hemorrhages had absorbed. V.R.F., 0.6; T..E., 1.1.

Case 5. G. L., aged thirty years. Family history for tuberculosis and hemophilia negative. He had the usual diseases of childhood and always had suffered from a severe form of constipation. When fourteen or fifteen years of age, the muscles of his legs became weak, and he devcloped a toe- drop; later this weakness progressed upward, and finally he lost the use of his legs. For a time he had incontinence of urine and feces, but has regained control of the bladder and bowels. X-ray examination of the spine was negative. Tonsils were removed five years ago. About seven years previously he was told that he had some weakness of the eye muscles, and a partial tenotomy of both external recti was done.

About nine months before examination, the vision of both eyes blurred rather suddenly, and he consulted an optician, who gave him glasses $(0.50$ spheres for cach eye) and assured him that his vision would improve if he wore them. The vision gradually improved and almost regained its former acuity. About the same time that the vision began to fail, he had a severe intestinal disturbance which confined him to his bed for several weeks.

The patient had been fecling well, and his eyes had been comfortable until two weeks before consultation. when the rision of the right eye suddenly failed. When first seen, April 15, 1921, V.R.F., 0.03 eccentric; L.F... 1.0. Ophthaimoscope : Right eye ; cornea and lens clear; vitreous filled with large masses of blood, which obscured all fundus details. I.eft eye: Cornea and lens clear; vitreous clear, excepting in lower temporal quadrant, in which location a Y-shaped, white, veil like mass of retinitis proliferans was letected; it extended forward into the vitreous about $7 \mathrm{D}$.. and slightly obscured the details of a branch of the lower temporal vein (Fig. 3). The veins were all slightly tortuous. The upper temporal vein was apparently obscured over a small area by thickened retina and a thin veil of scar tissue, which was located about 5 d.d. from the margin of the nerve (Fig. 4). Beyond the obscured area, the vein was convoluted in the region of a round mass of retinal pigment. A branch of the vein entered the main trunk near the mass of pigment. Folowing the branch from the main trunk toward the periphery, it was seen to 
cross the pigmented area, and a portion of it was covered by pigment. The vein then took a straight course and was bordered on both sides by a fine white streak, apparently a scar. It then suddenly thinned to about half or focal reaction was obtained after the administration of $5 \mathrm{mgm}$. subcutaneously. May 6, V.R.E., 0.2, eccentric. The vitreous had cleared quite decidedly, especially in the upper third of the upper temporal quadrant.

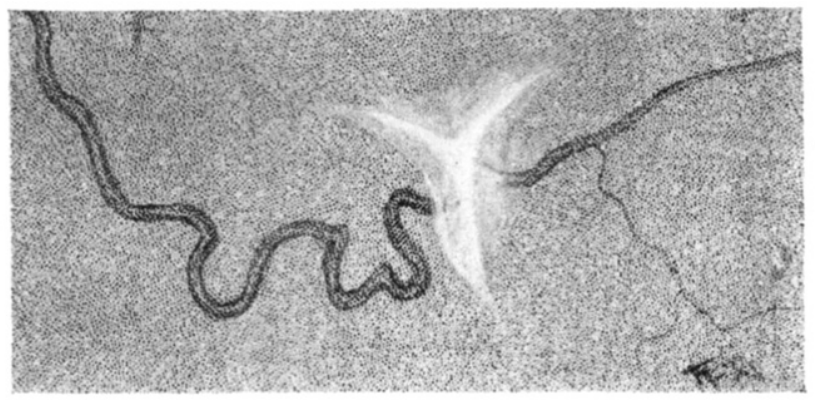

Fig. 3.-Retinitis proliferans and tortuous vein.

of its diameter and became very tortuous. The thinned portion of the vein had several branches: a lower branch of it crossed the main trunk, and its caliber was seen to be very much greater than the vein that it emptied into. Two or three round patches of retinal pigment were seen near veins on the nasal side of fundus (Fig. 5).
This covers a series of five cases of massive hemorrhages into the vitreous; all occurred in males; their ages ranged, at the time of the first attack, from twenty-five to forty-seven years. In all the cases the right eye was the first involved, and the greatest amount of destruction had taken place in it.

In Cases 1 and 3 a focal reaction oc-

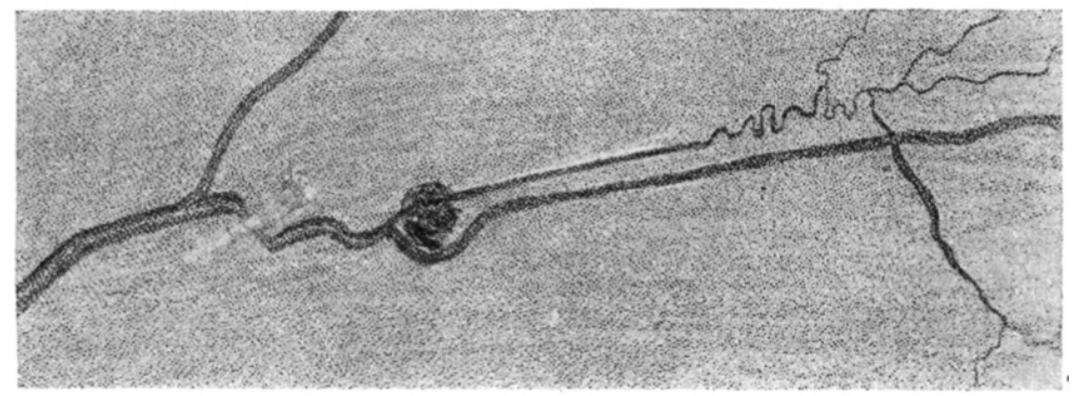

Fig. 4.- Irregular and tortuous veins. Retinitis proliferans. Area of retinal pigment changes.

There were no hemorrhages or exudates. The fundus changes were old, probably the result of inflammation which had occurred nine months before. The blood and spinal Wassermann reactions and the urine were negative. The teeth were negative, and nothing was found in the chest. Blood pressure, $125 \mathrm{~mm}$. of mercury. Old tuberculin was given for diagnostic purposes, and no constitutional curred following the administration of tuberculin, and in Case 2 the man had pulmonary tuberculosis and lost weight just before the occurrence of the intraocular hemorrhage. Cases 1 and 3 improved after the administration of tuberculin, and Case 2 improved with the improvement of his general health. In Cases 1 and 2 there was a visible periphlebitis with patches of white and yellowish exudate in the 
proximity of the veins; and in Case 1 these patches were seen to spread along the veins and preceded the hemorrhages. Cases 1, 2 and 3 were due to tuberculosis. In all the cases the veins were tortuous and irregular in caliber, and the peripheral branches were frequently relatively larger than normal when compared with the main trunk. In Case 1, and apparently in Cases 3, 4, and 5 , the earlier changes were in the periphery of the fundus in the beginning, before the appearance of hemorrhages. In Case 4, the inflam-
4. Focal infection is a possible cause.

5. Hemophilia is not a cause, but might be a contributing factor.

6 . The hemorrhages are the result of a localized pathologic weakening of the bloodvessels, and increased blood pressure or exercise are only exciting causes.

7. The veins are ustally attacked.

8. In some cases there is involvement of the retina early in the disease.

9. In most cases the earlier changes occur in the periphery of the eye, and if patients were examined in the early

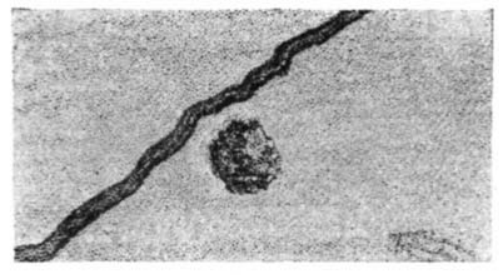

Figr. S.-Mass of retinal pigment near fortuonis vein.

matory process was most marked in the retina, and in Case 5 , there were patches of retinal pigment which was secondary to retinal inflammation. In Cases 4 and 5 tuberculosis was excluded: the possible cause of 4 was focal infection from abscesses at the apices of teeth and infected tonsils. In Case 5 the attacks were associated with severe intestinal disturbance, and the possibility of focal infection from the intestines was considered.

The conclusions derived from the study of the literaturc and the foregoing cases are:

1. Recurrent hemorrhages into retina and vitreous in young persons is probably not a specific disease.

2. Tuberculosis of the retinal vesseis, especially the veins, is one of the common etiologic factors.

(a) To prove that the cause is tuberculous, a focal reaction should be obtained.

(b) When due to tuberculosis, improvement follows the administration of tuberculin and hygienic treatment.

3. Syphilis is an occasional cause. stages of the disease, we would learn more about the pathology.

10. Retinitis proliferans occurs in most cases.

11. I believe the disease is primarily in the retina, and that the partial or complete detachment of the retina is due to traction from scar tissue and inot to subretinal hemorrhages from the choroidal vessels, as has been suggested.

12. The prognosis is poor; both eyes usually become affected, and in most cases the vision is markedly diminished.

13. The discase is much more frequent in men. When occurring in women, it is usually not so severe.

I have reviewed all the literature 'that was available and collected 110 cases. This material has been arranged in tabular form (See Transactions Amer. Ophth. Soc., v. 19, p. 248), giving the sex; age of the patient at the time of the first hemorrhage; the etiology; the first eye to become involved; whether the second eye was attacked; and the bibliography. 
BIBLIOGRAPHY.

1. Ciracfe, $x$. Graefe's Arch. f. Ophth., i, 1855.

2. American Encyclopedia of Ophth., viii, 5802 .

3. Eales. Birmingham Med. Rev., July, 1880. Ophth. Rev., i, 1882, p. 41.

4. Beaumont. Ophth. Rev., ii, 1892, p. 352.

5. Hutchinson. Ophth. Rev., ii, 1882, p. 41.

6. Jacqueau. Ophth. Rev., xvii, 1889, p. 323.

7. Noll. Arch. f. Augenh., lxiii, 1909, p. 213.

8. Kipp. Arch. of Ophth,, xxxviii, 1909, p. 349.

9. Kipp. Trans. of Amer. Ophth. Soc., 1895, p. 423.

10. Axenfeld. Bull. de la Soc. Belge d'Opht.: No. 29. 1910-11, p. 115; also Axenfeld and Stock. Klin. M. f. Augenh., xlvii, I, 146, 1909.

11. Igersheimer. Graefe's Arch. f. Ophth., xxxii, p. 215.

12. Harms. Klin. M. f. Augenh., July, 1912, 106.

13. Jackson. Trans. Colorado Ophth, Cong eis, 1915, p. 207.

14. Moissonnicr. Soc. d'Opht. de Paris, 1911 p. 110.

15. Zentmayer. Amer. Jour. Ophth., 1920, 65;

\title{
CONGENITAL ANTERIOR CAPSULAR CATARACT.
}

\author{
L. D. Brose, M.D., F.A.C.S. \\ EVANSVILLE, INI.
}

The history of five cases of congenital anterior capsular cataract occurring in three sisters and two brothers is here given together with the operative treatment resorted 10 . Read at the Philadelphia meeting of the American Academy of Ophthalmology and Otolaryngology, October, 1921.

The interest in this paper centers in that an entire family, consisting of five children, all developed in both eyes congenital anterior capsular cataract; again that in three of the women we found corneal opacities; and that the capsular cataract in two of the women was followed later in life by total lens opacity with subsequent liquefaction of the lens fibers. Again in Case 2, after rision had been restored in childhood by an iridectomy made downward and inward and remained good thruout school life and early womanhood, it was again lost for some six years, probably thru lens displacement, then spontaneously restored only to be again lost because of lens displacement into the iridectomy coloboma. And lastly in the operative measures undertaken for sight restoration.

The following are the case histories of this family:

CASF 1. A. V. B., aged 35 years, a resident of Clay, Ky., consulted me May 7, 1914. Father and mother living and have good eyesight. $\mathrm{He}$ is married, robust in appearance and the father of a son ten years old with good sight. He has no recollection of ever having had a sore eye. The cornea shows no evidence of previous disease and the pupils react to light. Occupying the central pupillary area, we found a circumscribed whitish opacity lying within the anterior lens capsule but in front of the lens. Surmounting the opacity is seen a small spurlike elevation of clearer consistency and more grayish appearance. Vision: O.D., $15 / 80$ and Snellen $D=1.50$; O.S., the counting of fingers at five feet. Ophthalmoscopic examination with plane mirror, after cocain mydriasis, disclosed the lenses transparent and the fundus healthy.

A limited needling of the left lens was made with but slight reaction and at the expiration of six days he left the hospital with instructions to continue the daily use of atropin. On July 20 over half of the lens substance had been absorbed, and he counted fingers at ten feet. A more extensive needling was made, the atropin continued with an ultimate result of vision +12.00 $=15 / 40$ and Sn. I) $=0.65$ with +16.00 . The original capsular thickening remains but is displaced upward under the upper pupillary border. 